\title{
PERCEPÇÖES DOS ATORES SOCIAIS QUE COORDENAM PROGRAMAS DE ATENÇĀO ÀS CRIANÇAS E AOS ADOLESCENTES EM SITUAÇĀO DE RUA NO MUNICÍPIO DE RIBEIRÃO PRETO - SP '
}

Marcelo Medeiros ${ }^{2}$

\section{Professora Orientadora: Maria das Graças Carvalho Ferriani.}

O propósito deste estudo é conhecer e compreender as percepções dos atores sociais que planejam e/ou coordenam programas assistenciais para crianças e adolescentes que vivem em situação de rua na cidade de Ribeirão Preto - SP. Como objetivo buscamos identificar os programas desenvolvidos na cidade, e, através dos coordenadores dos programas, também identificar a compreensão que têm sobre crianças e adolescentes em situação de rua e o significado destes programas para esses atores sociais. Orientamos o desenvolvimento deste estudo por um referencial teórico-metodológico qualitativo que pretende compreender o tema de modo particular, sem generalizá-lo. O material para análise foi coletado através da observação livre, entrevista semi-estruturada e análise de documentos oficiais. Os dados oriundos deste processo foram analisados à luz da proposta da hermenêutica-dialética elaborada por Minayo (1993). A análise realizada nos permitiu conhecer alguns aspectos sobre a compreensão dos atores sociais a respeito das crianças e adolescentes em situação de rua bem como o que significam para eles os programas assistenciais desenvolvidos para este grupo em Ribeirão Preto (SP). Compreendendo a complexidade da questão, apontamos que, numa fase anterior ao planejamento de quaisquer programas de atenção às crianças e aos adolescentes que vivem em situação de rua, neste caso em Ribeirão Preto, há necessidade de conhecermos seu perfil e suas necessidades a partir delas mesmas, de forma a garantir o mínimo de resolutividade de qualquer projeto.

\footnotetext{
${ }^{1}$ Dissertação de Mestrado. EERP-USP - São Paulo.

${ }^{2}$ Prof. Assistente do Centro de Graduação em Enfermagem, Departamento de Enfermagem em Educação e Saúde Comunitária da Autarquia Federal Faculdade de Medicina do Triângulo Mineiro, Uberaba, Minas Gerais.
} 